УДК 665.658.62

МАТЕМАТИЧЕСКОЕ МОДЕЛИРОВАНИЕ ПРОЦЕССА РАЗДЕЛЬНОЙ ГИДРООЧИСТКИ ПРЕДВАРИТЕЛЬНО ФРАКЦИОНИРОВАННОГО ДИЗЕЛЬНОГО ТОПЛИВА

\title{
MATHEMATICAL MODELING OF THE PROCESS OF SEPARATE HYDROTREATING OF PRE-FRACTIONATED DIESEL FUEL
}

\author{
В.А. Жилина, Н.А. Самойлов \\ Уфимский государственный нефтяной технический университет, \\ г. Уфа, Российская Федерация \\ Valeria A. Zhilina, Naum A. Samoilov \\ Ufa State Petroleum Technological University, Ufa, Russian Federation \\ e-mail: naum.samoilow@yandex.ru
}

Аннотация. Выполнен анализ особенностей гидроочистки дизельного топлива в различных технологических схемах компоновки реакторных блоков. Показаны преимущества раздельного гидрирования предварительно фракционированного сырья, позволяющего наиболее эффективно использовать особенности катализа реакций гидродеобессеривания для различных сераорганических веществ. Обоснована необходимость учета в математической модели процесса детальной характеристики сырья гидроочистки по сераорганическим примесям при его раздельном гидрировании.

Предложен принцип математического моделирования гидроочистки дизельного топлива путем представления исходного сырья в виде совокупности узких фракций, в каждой из которых содержание разнообразных сераорганических соединений рассматривается как условный псевдокомпонент. Модель легко адаптируется под любое сырье 
при изменении его состава по общей сере заданием ее концентрации в соответствующем псевдокомпоненте по фактическим аналитическим данным или функцией распределения серы по псевдокомпонентам сырья при решении аналитических задач.

В статье рассмотрена задача оценки влияния числа узких фракций, на которое условно делится исходное сырье, и характера распределения сераорганических примесей (псевдокомпонентов) по узким фракциям сырья на выбор границы деления сырья на узкую и тяжелую фракции и загрузку катализатора в реакторы, необходимую для достижения заданной глубины гидроочистки. Выполнено математическое моделирование процесса раздельной гидроочистки предварительно фракционированного сырья на широкие легкую и тяжелую фракции в двух реакторах в виде 200 вариантов расчетов с исследованием влияния деления исходного сырья на 16, 8 и 4 узких фракций, в которых совокупные сераорганические компоненты рассматривались как псевдокомпоненты, и разнообразных распределений сераорганики по узким фракциям на загрузку катализатора в реакторы.

Abstract. The analysis of features of diesel fuel hydrotreating in various technological schemes of reactor block layout is performed. The advantages of separate hydrogenation of pre-fractionated raw materials are shown, which allows the most effective use of the features of catalysis of hydrode-desulfurization reactions for various organosulfur substances. The necessity of taking into account in the mathematical model of the process the detailed characteristics of the raw material of hydrotreating for sulfur-organic impurities during its separate hydrogenation is justified. The principle of mathematical modeling of diesel fuel hydrotreating by presenting the feedstock as a set of narrow fractions, in each of which the content of various organosulfur compounds is considered as a conditional pseudo-component, is proposed. The model is easily adapted to any feedstock when its composition changes in terms of total sulfur by specifying its concentration in the corresponding pseudo-component according to actual 
analytical data or by the function of sulfur distribution over pseudo-components of raw materials when solving analytical problems.

The article considers the problem of assessing the influence of the number of narrow fractions into which the feedstock is conventionally divided, and the nature of the distribution of organosulfur impurities (pseudo-components) over narrow fractions of the feedstock on the choice of the borderline for dividing the feedstock into narrow and heavy fractions and the loading of the catalyst into the reactors necessary to achieve a given depth hydrotreating. Mathematical modeling of the process of separate hydrotreating of pre-fractionated feedstock into broad light and heavy fractions in two reactors in the form of 200 variants of calculations with the study of the effect of dividing the feedstock into 16, 8 and 4 narrow fractions, in which the total organosulfur components were considered as pseudocomponents, and various distributions organosulfur in narrow fractions for loading the catalyst into reactors.

Ключевые слова: математическое моделирование; дизельное топливо; гидроочистка; сераорганические компоненты; псевдокомпоненты; реакторный блок; предварительное фракционирование; деление сырья

Key words: mathematical modeling; diesel fuel; hydrotreating; organic sulfur components; pseudo-components; reactor block; pre-fractionation; raw materials division

Производимое с пятидесяти процентным профицитом дизельное топливо является одним из основных продуктов российского экспорта с направлением его преимущественно в страны Европейского союза, предъявляющего ввиду ухудшения экологической ситуации в мире повышенные требования к качеству товарной продукции по стандарту Евро [1]. Согласно введенным в 2015 г. на территории ЕС стандарту Евро-6 и в Российской Федерации стандарту Евро-5, содержание сернистых соединений в дизельном топливе не должно превышать 10 ppm [2]. 
Пока требования к содержанию серы в товарной продукции были достаточно низкие, нужная глубина обессеривания по классической однореакторной схеме (рисунок 1, а) [3] достигалась обычным варьированием параметров ведения процесса до оптимальных значений для химического превращения: повышением температуры на входе в реактор, уменьшением объемной скорости сырья, повышением давления в реакторе, увеличением кратности циркуляции водородсодержащего газа. Одновременно шло изучение свойств различных катализаторов и влияния их состава на ведение процесса. Так в скором времени произошла замена катализаторов на более эффективные и устойчивые к коксообразованию, что также ненадолго способствовало увеличению глубины обессеривания исходного сырья $[4,5]$. По мере ужесточения требований по допустимому содержанию сернистых соединений в дизельном топливе сначала должное качество очистки обеспечивалось путем простого увеличения времени пребывания исходного сырья в реакторе за счет легко реализуемого монтажа двух или трех последовательно расположенных реакторов (рисунок 1, б), а также подаче сырья параллельно в два идентичных реактора, фактически представляющих собой единичный реактор с увеличенным количеством катализатора [6]. По мере дальнейшего утяжеления сырья установок гидроочистки дизельного топлива вкупе с обеспечением ультранизкого содержания серы в продукции этих установок, было предложено предварительное фракционирование исходного сырья с раздельным гидрированием фракций с разной температурой кипения (рисунок 1, в) [7, 8]. Такая схема позволяла достичь более глубокой гидроочистки сырья. 


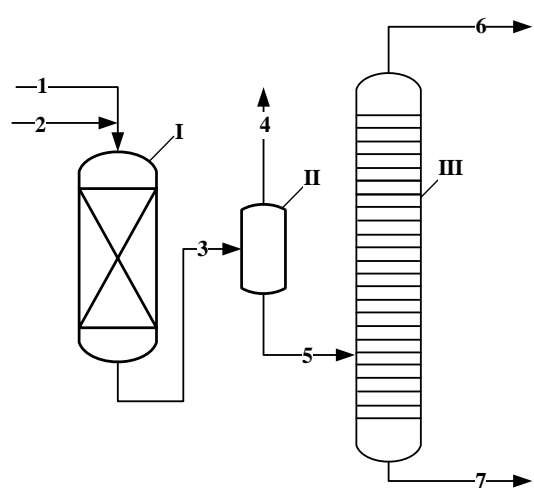

$\mathrm{a}$

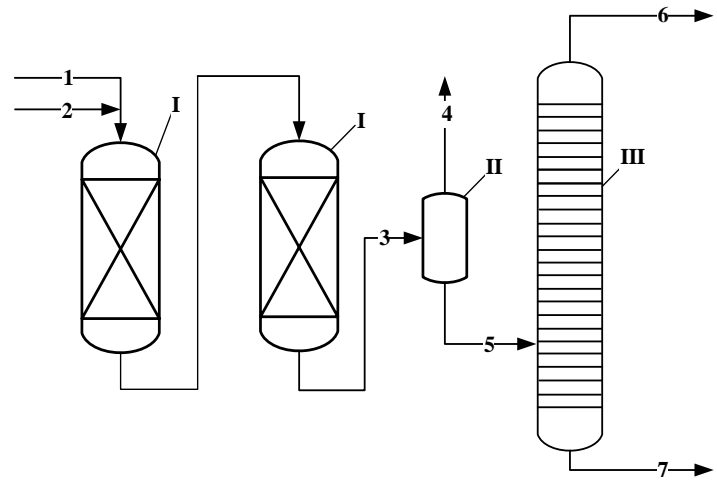

б

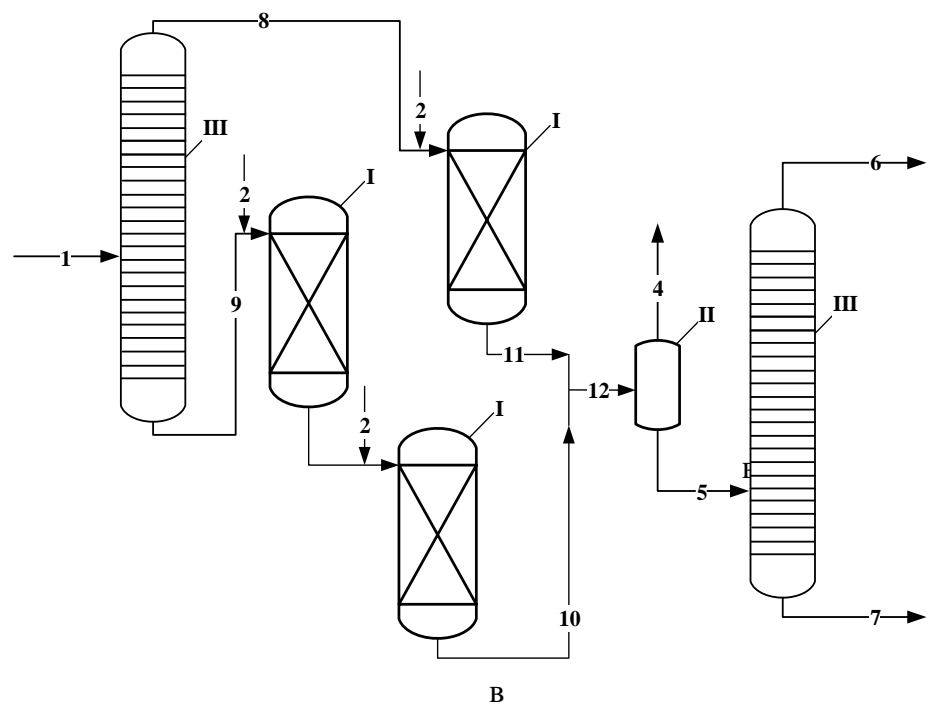

I - реактор; II - сепаратор; III - ректификационная колонна;

1 - сырье; 2 - ВСГ; 3 - продукты реакции;

4 - ВСГ в смеси с сероводородом;

5 - нестабильный гидрогенизат;

6 - углеводородные газы; 7 - очищенный дистиллят;

8 - фракция $180-300{ }^{\circ} \mathrm{C}$ дизельного топлива;

9 - фракция $300-360{ }^{\circ} \mathrm{C}$ дизельного топлива;

10-12 - очищенный гидрогенизат

a) однореакторная схема;

б) последовательная двухреакторная схема;

в) трехреакторная схема)

Рисунок 1. Схемы реализации процесса гидроочистки дизельного топлива

Главными недостатками предложенной новой технологии являются жесткая и достаточно произвольная, без учета реального содержания сернистых соединений и интенсивности их гидрирования, граница деления легкой и тяжелой фракции без обоснования ее позиции и практически невозможность априорного расчета процесса. 
С целью дальнейшей модернизации действующих установок гидроочистки дизельного топлива и оптимизации процесса в целом стала актуальной задача создания математических моделей процесса, которые могли бы учитывать кинетические закономерности для широкого ряда разных типов сернистых соединений, вступающих в реакции гидрирования. Появились предложения целого ряда кинетических моделей процесса гидроочистки с разной степенью формализации: степенные функции общего содержания серы $[9,10]$, системы уравнений для разных классов серасодержащих соединений и для сернистых соединений разной степени гидрирования. Общей особенностью этих моделей является эффективный характер констант скоростей реакций, который не дает полноценного представления о кинетике многокомпонентного процесса. А трудоемкость и затратность идентификации не только десятков индивидуальных серасодержащих соединений, но и многочисленных классов таких соединений, при условии их низкого по отдельности содержания в исходном сырье не позволяют досконально учесть все особенности химических превращений веществ [11-13].

В ряде исследований предлагалось рассматривать отдельные классы сераорганических примесей в расчетах как псевдокомпоненты [13, 14], однако такой подход приемлем только при моделировании единичных реакторов или их последовательности, но не при раздельном гидрировании фракций исходного сырья, так как компоненты одного класса могут оказаться размытыми по всему дизельному топливу [15]. В связи с этим нами предложено разделять сырье гидроочистки на несколько фракций и совокупность сераорганических примесей по общей сере в каждой фракции рассматривать как условный псевдокомпонент [16]. Такой прием позволяет при расчете процесса раздельной гидроочистки предварительно фракционированного дизельного топлива:

- учитывать особенности кинетики реакций гидродесульфуризации в узких фракциях; 
- существенно упростить стадию подготовительных лабораторных экспериментов для определения кинетических характеристик реакций гидродесульфуризации по общей сере для псевдокомпонентов по сравнению с представлением псевдокомпонентов как дополнительно выделенных из сырья конкретных классов сераорганических веществ;

- расчетным путем определять такую границу деления исходного сырья на широкие легкую и тяжелую фракции, состоящие в свою очередь из набора узких фракций, при которой необходимая для реализации процесса загрузка катализатора будет минимальной.

В данной статье рассмотрена задача оценки влияния числа узких фракций, на которое условно делится исходное сырье, и характера распределения сераорганических примесей (псевдокомпонентов) по узким фракциям сырья на выбор границы деления сырья на легкую и тяжелую фракции и загрузку катализатора в реакторы, необходимую для достижения заданной глубины гидроочистки. Задача решалась методом математического моделирования реакторного узла установки гидроочистки с раздельным гидрированием легкой и тяжелой фракций сырья (рисунок 2).

В качестве базового сырья процесса гидроочистки была взята прямогонная фракция дизельного топлива $180-360{ }^{\circ} \mathrm{C}$ с установки Л-24-5 филиала ПАО АНК «Башнефть» «Башнефть-Уфанефтехим» с содержанием общей серы 20000 ppm.

Основой математического моделирования служило разбиение ИТК (рисунок 3) на $\mathrm{N}$ равных узких фракций, например, по 6.25 \% об. при $\mathrm{N}=16$, в каждой из которых сераорганика по общей сере рассматривалась как і-ый псевдокомпонент. 


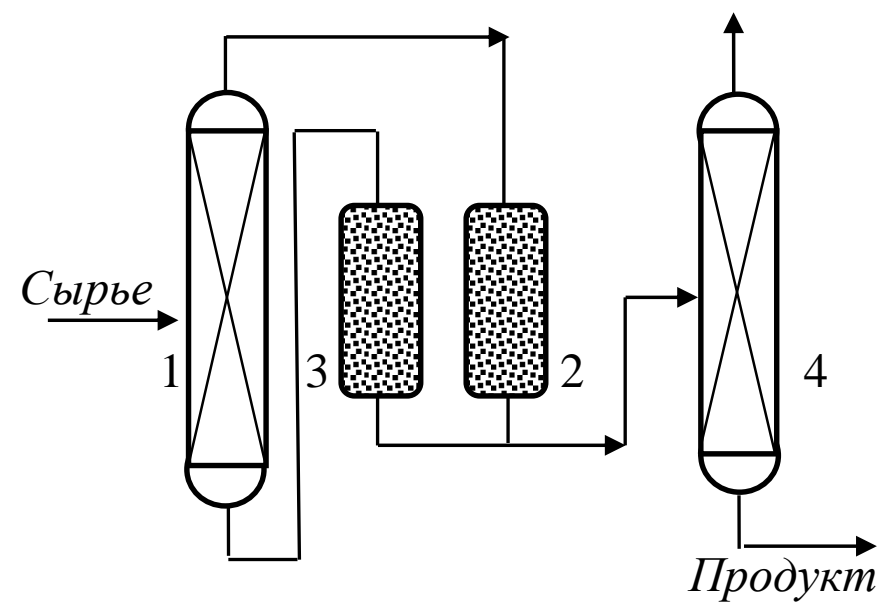

1 - ректификационная колонна;

2 - реактор Р-1 для гидрирования легкой фракции сырья;

3 - реактор Р-2 для гидрирования тяжелой фракции сырья;

4 - стабилизатор

Рисунок 2. Компоновка реакторного блока с гидрированием сырья, предварительно разделенного на легкую и тяжелую фракции

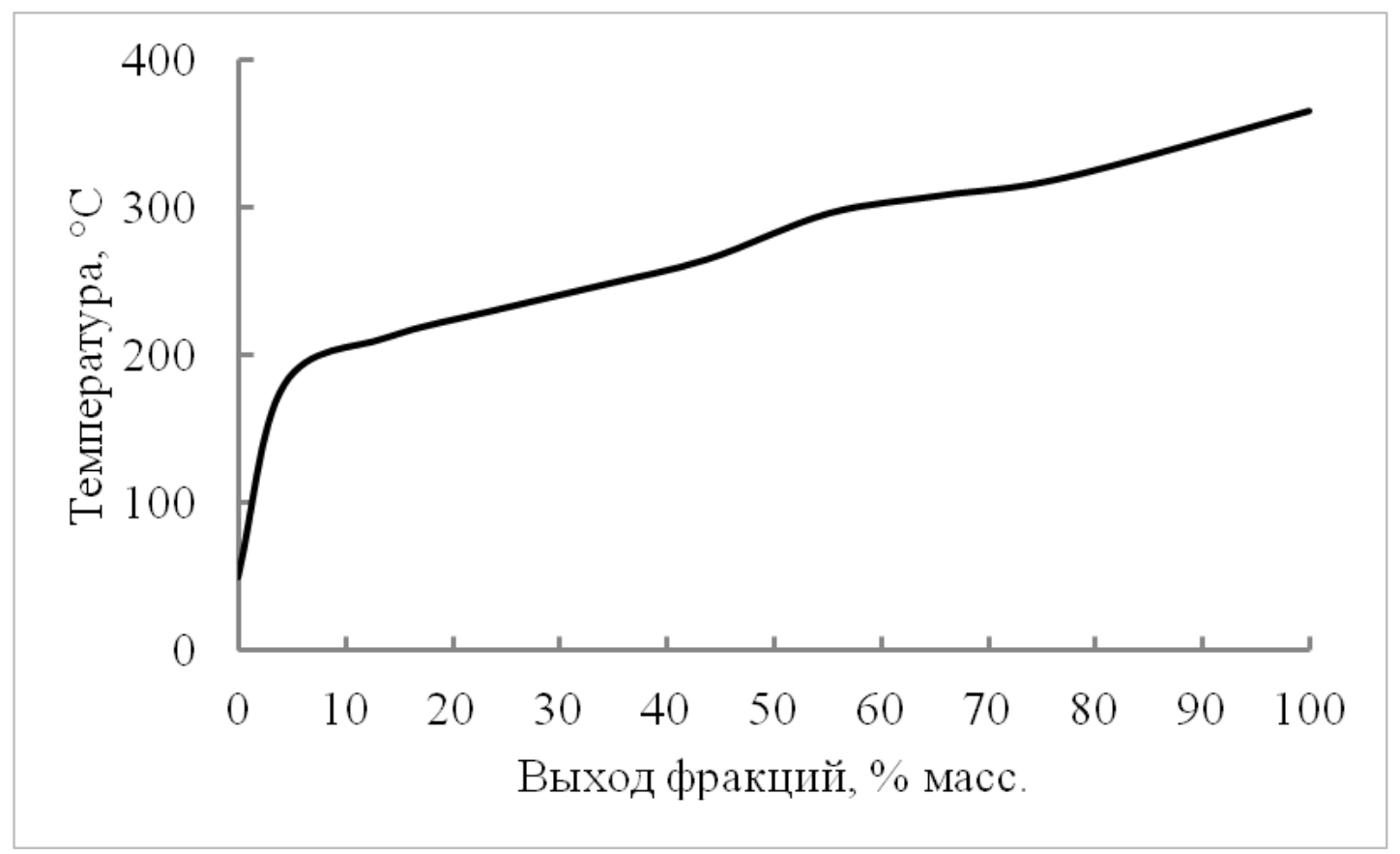

Рисунок 3. Кривая ИТК прямогонного дизельного топлива

В качестве допущения при формировании математической модели было принято, что реакция гидродесульфирования псевдокомпонентов описывается как изотермическая реакция первого порядка, протекающая в реакторе с гидродинамикой идеального вытеснения при постоянстве прочих параметров (расход сырья, давление, температура, расход 
водородсодержащего газа, активность катализатора и удельный объемный расход сырья по отношению к объему катализатора), что позволяло достаточно корректно сопоставлять между собой результаты расчета при варьировании числа узких фракций и распределения серы между ними. В общем виде математическая модель гидроочистки дизельного топлива имеет следующий вид:

$$
\left.\begin{array}{c}
\frac{d C_{S 1}}{d \tau}=-K_{2} C_{S 1} \\
\frac{d C_{S 2}}{d \tau}=-K_{2} C_{S 2} \\
\vdots \\
\frac{d C_{S i}}{d \tau}=-K_{i} d C_{S i} \\
\frac{C_{S N}}{d \tau}=-K_{N} d C_{S N}
\end{array}\right\}
$$

где $C_{\mathrm{Si}}$ и $K_{\mathrm{i}}-$ соответственно концентрация і-го сераорганического псевдокомпонента и эффективная константа скорости і-й реакции.

Модель позволяет рассчитать время контакта реакционной смеси с катализатором $\tau$ для достижения концентрации серы $C_{R S_{\tau}}$ меньше допустимой концентрации серы в очищенном дизельном топливе :

$$
C_{R S_{\tau}}=C_{S 1}+C_{s 2}+C_{S 3}+\cdots+C_{S N}<C_{\text {Sдоп }}
$$

и необходимый объем катализатора, загружаемого в реактор.

При раздельной подаче широких легкой и тяжелой фракций сырья в каждом из реакторов реализуется математическая модель с варьируемым числом узких фракций. Исследование процесса гидроочистки при делении исходного сырья установки на 16 узких фракций было выполнено для 15 вариантов деления сырья на две широкие фракции (таблица 1). 
Таблица 1. Варианты распределения 16 узких фракций по реакторам: Р-1 (легкая фракция сырья) и Р-2 (тяжелая фракция сырья)

\begin{tabular}{|c|c|c|c|c|c|c|c|c|}
\hline \multirow{2}{*}{ 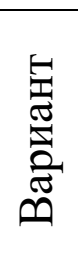 } & \multicolumn{2}{|c|}{$\begin{array}{c}\text { Ввод узких } \\
\text { фракций в } \\
\text { реакторы }\end{array}$} & \multirow{2}{*}{ 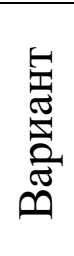 } & \multicolumn{2}{|c|}{$\begin{array}{c}\text { Ввод узких } \\
\text { фракций в } \\
\text { реакторы }\end{array}$} & \multirow{2}{*}{ 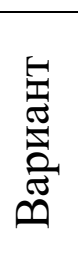 } & \multicolumn{2}{|c|}{$\begin{array}{c}\text { Ввод узких } \\
\text { фракций в } \\
\text { реакторы }\end{array}$} \\
\hline & P-1 & P-2 & & $\mathrm{P}-1$ & P-2 & & P-1 & P-2 \\
\hline 1 & 1 & $2 \ldots 16$ & 6 & $1 \ldots 6$ & $7 \ldots 16$ & 11 & $1 \ldots 11$ & $12 \ldots 16$ \\
\hline 2 & 1,2 & $3 \ldots 16$ & 7 & $1 \ldots 7$ & $8 \ldots 16$ & 12 & $1 \ldots 12$ & $13 \ldots 16$ \\
\hline 3 & $1 \ldots 3$ & $4 \ldots 16$ & 8 & $1 \ldots 8$ & $9 \ldots 16$ & 13 & $1 \ldots 13$ & $14 \ldots 16$ \\
\hline 4 & $1 \ldots 4$ & $5 \ldots 16$ & 9 & $1 \ldots 9$ & $10 \ldots 16$ & 14 & $1 \ldots 14$ & 15,16 \\
\hline 5 & $1 \ldots 5$ & $6 \ldots 16$ & 10 & $1 \ldots 10$ & $11 \ldots 16$ & 15 & $1 \ldots 15$ & 16 \\
\hline
\end{tabular}

Выполнялось также исследование гидроочистки сырья при делении его на 8 и 4 узких фракции, каждая из которых являлась совокупностью, соответственно, двух и четырех узких фракций начальных 16 узких фракций, с соответствующим исчерпывающим варьированием состава широких фаз, поступающих в два реактора.

Предварительно была выполнена верификация математической модели с приемлемой близостью результатов моделирования и характеристик промышленных реакторов гидроочистки дизельного топлива.

Модель легко адаптируется под любое сырье при изменении его состава по общей сере заданием еe концентрации в соответствующем псевдокомпоненте по фактическим аналитическим данным или функцией распределения серы по псевдокомпонентам сырья при решении аналитических задач.

В соответствии с постановкой задачи исследования в настоящей работе было исследовано 8 гипотетических вариантов распределения общей серы по 16 псевдокомпонентам в пределах от 1000 до 52500 ppm (таблица 2, рисунок 4), характеризующих линейные распределения (варианты 1 и 2), линейно возрастающее с переменной амплитудой колебаний концентрации серы, отражающее произвольное распределение серы по псевдокомпонентам (формально - знакопеременное распределение, вариант 3), нелинейные с экстремумом типа максимум (варианты 4-6), нелинейное 
с экстремумом типа минимум (вариант 7), нелинейное возрастающее (вариант 8). При расчете концентрации общей серы для і-го псевдокомпонента в уравнениях для вариантов 4-8 использовалась величина $\mathrm{G}_{\mathrm{i}}$ - доля отобранных узких фракций от первой по i-ю в процентах объемных.

Численные значения эффективных констант скорости реакции для 16 узких фракций псевдокомпонентов приняты в порядке убывания от 16 ч$^{-1}$ для 1-ой узкой фракции с легкогидрируемыми серасодержащими соединениями до 1 ч ${ }^{-1}$ для 16-ой узкой фракции с трудногидрируемыми серасодержащими соединениями, что также отражает лимитирующий характер реакций последних. В случае разделения сырья на 4 и 8 фракций псевдокомпонентов для каждой фракции принималось наименьшее значение константы скорости из составляющих ее узких фракций.

Таблица 2. Характеристика модельного сырья по распределению содержания общей серы в псевдокомпонентах

\begin{tabular}{|c|c|c|c|c|}
\hline 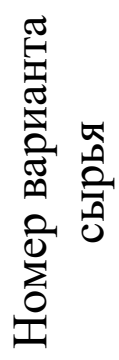 & $\begin{array}{c}\text { Формула для расчета } \\
\text { концентрации общей серы } \\
\text { в і-м псевдокомпоненте }\end{array}$ & 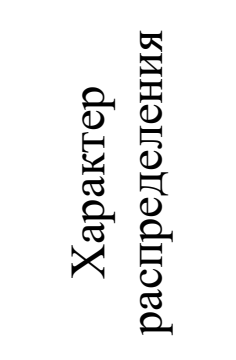 & 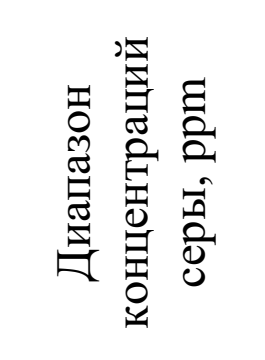 & 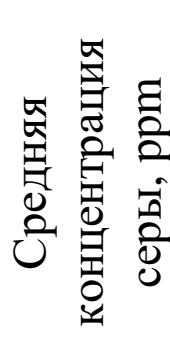 \\
\hline 1 & $\mathrm{~S}=2000 * \mathrm{i}$ & линейное & $2000-32000$ & 17000 \\
\hline 2 & $S=2000 *(17-i)$ & линейное & $2000-32000$ & 17000 \\
\hline 3 & $\mathrm{~S}=2000+(-1)^{\mathrm{i}+1 * 1500 * \mathrm{i}}$ & переменное & $1000-52500$ & 16250 \\
\hline 4 & $\mathrm{~S}=2000+720 * \mathrm{G}_{\mathrm{i}}-8,2 * \mathrm{G}_{\mathrm{i}}^{2}+0,009 * \mathrm{G}_{\mathrm{i}}^{3}$ & нелинейное & $1000-18625$ & 12841 \\
\hline 5 & $\mathrm{~S}=5000+800 * \mathrm{G}_{\mathrm{i}}-8 * \mathrm{G}_{\mathrm{i}}^{2}$ & нелинейное & $5000-25000$ & 18281 \\
\hline 6 & $\mathrm{~S}=15000+300 * \mathrm{G}_{\mathrm{i}}-4 * \mathrm{G}_{\mathrm{i}}^{2}$ & нелинейное & $5000-20625$ & 16328 \\
\hline 7 & $\mathrm{~S}=15000-100 * \mathrm{G}_{\mathrm{i}}+3 * \mathrm{G}_{\mathrm{i}}^{2}$ & нелинейное & $14180-35000$ & 20645 \\
\hline 8 & $\mathrm{~S}=15000-300 * \mathrm{G}_{\mathrm{i}}+3 * \mathrm{G}_{\mathrm{i}}^{2}$ & нелинейное & $7500-15000$ & 10020 \\
\hline
\end{tabular}




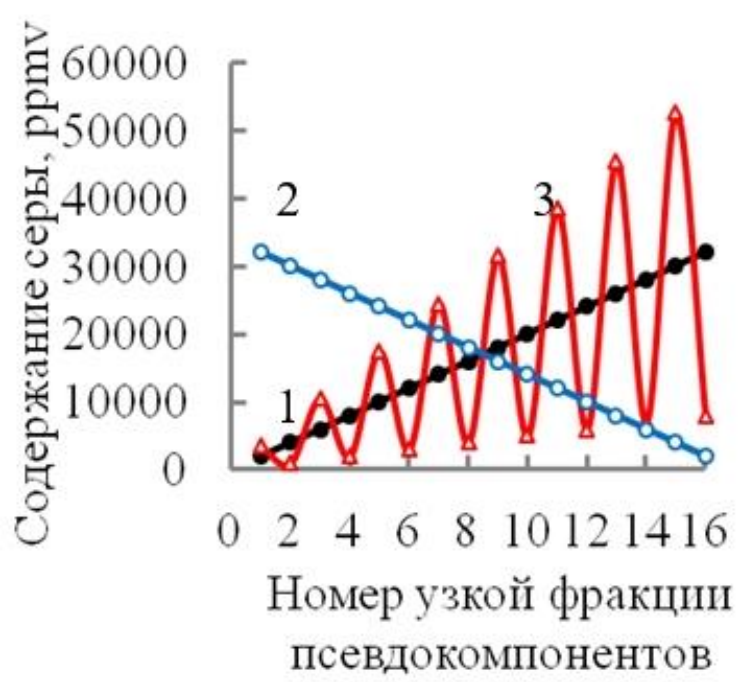

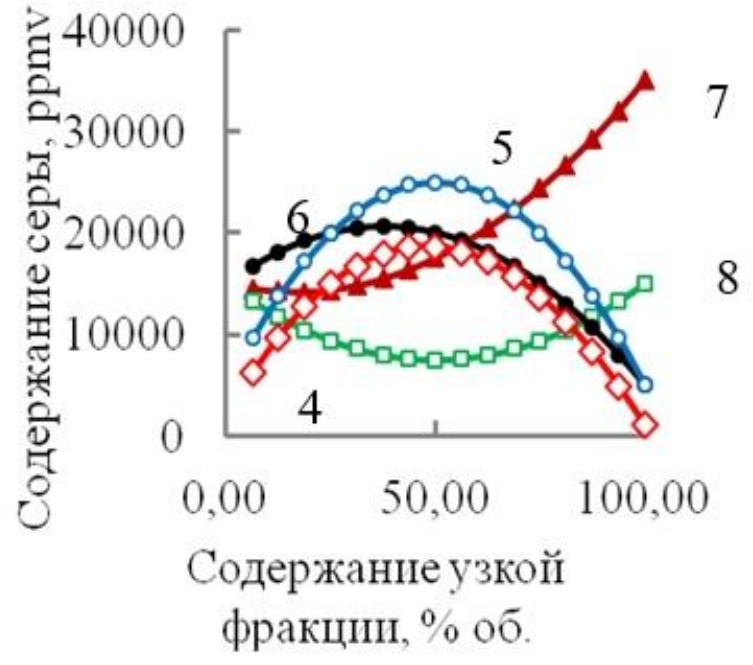

1-8 - номера вариантов сырья по таблице 2

Рисунок 4. Распределение общей серы сырье гидроочистки

Расчет процесса гидроочистки выполнялся последовательно для каждого реактора для конкретного варианта ввода псевдокомпонентов с широкими легкой и тяжелой фракциями сырья совместным решением систем 16, 8 или 4 дифференциальных уравнений методом Рунге-Кутто первого порядка с шагом интегрирования 0.0001 ч с периодической фиксацией концентрации серы по псевдокомпонентам во времени. Расчет кинетики продолжался по времени $\tau$ до тех пор, пока в продукте на выходе из каждого реактора суммарная концентрация серы по псевдокомпонентам не превышала $10 \mathrm{ppm}$. Далее по времени реакции рассчитывалась загрузка катализатора в каждый реактор и в реакционный блок в целом.

В качестве критерия оптимальности был выбран минимальный суммарный объем загружаемого катализатора для обеспечения глубины очистки $100 \mathrm{~m}^{3} /$ ч сырья до уровня $\mathrm{C}_{\text {Sдоп }}=10 \mathrm{ppm}$.

Всего было выполнено по 25 вариантов расчета двухреакторного блока процесса гидроочистки для каждого из 8 вариантов состава исходного сырья по общей сере. Для первого варианта состава ( $\mathrm{S}=2000 * \mathrm{i})$ детальные результаты моделирования для 16, 8 и 4 узких фракций приведены в таблице 3, некоторые результаты расчетов для 4 узких фракций графически 
представлены на рисунке 5. Во всех 200 вариантах расчета загрузка катализатора в два реактора была в 1.5-2.0 раза меньше, чем при гидроочистке всего сырья (т.е. всех псевдокомпонентов) в одном реакторе.

Для анализируемой двухреакторной схемы гидроочистки (рисунок 2) за счет разного расхода легкой и тяжелой фракций, загружаемых в реактора Р1 и Р-2, целесообразно большую легкогидрируемую часть сырья с преобладанием соответствующих псевдокомпонентов очистить до необходимой глубины в реакторе Р-1 при относительно небольшой загрузке катализатора, а меньшую трудногидрируемую часть сырья очистить до необходимой глубины в реакторе Р-2 при большей загрузке катализатора, что в итоге обеспечивает снижение суммарного объема загружаемого в оба реактора катализатора (рисунок 5,8 ).

Более того, при увеличении числа псевдокомпонентов наблюдается характерное их распределение по реакторам и, соответственно, эквивалентная этому распределению граница деления широких легкой и тяжелой фракций сырья, при которой процесс гидроочистки может быть реализован с минимизацией загрузки катализатора в оба реактора.

Аналогичные закономерности наблюдались и во всех остальных вариантах распределения общей серы в исходном сырье (варианты № 2-№ 8, таблица 2), поэтому для них в таблице 4 приведены только сводные данные по общей загрузке катализатора в оба реактора.

Анализ общих данных таблиц 3 и 4 для вариантов распределения общей серы № 1-№ 3, характеризующихся по сущности линейными законами, показал, что при учете 16 узких фракций в сырье граница деления, обеспечивающая минимизацию загрузки катализатора в оба реактора смещается с позиции между псевдокомпонентами 13 и 14 на позицию между псевдокомпонентами 14 и 15 по мере увеличения концентрации сераорганики в широкой тяжелой фракции с 32000 до 52500 ppm. 
Таблица 3. Результаты гидроочистки дизельного топлива для варианта №1 по распределению общей серы по узким фракциям при различном распределении псевдокомпонентов по легкой и тяжелой фракциям сырья по реакторам

\begin{tabular}{|c|c|c|c|c|c|c|c|c|c|c|c|c|c|}
\hline \multicolumn{3}{|c|}{ P-1 } & \multicolumn{3}{|c|}{$\mathrm{P}-2$} & \multirow[b]{2}{*}{ 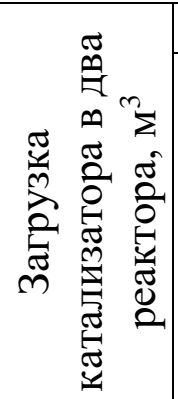 } & \multicolumn{3}{|c|}{$\mathrm{P}-1$} & \multicolumn{3}{|c|}{$\mathrm{P}-2$} & \multirow[b]{2}{*}{ 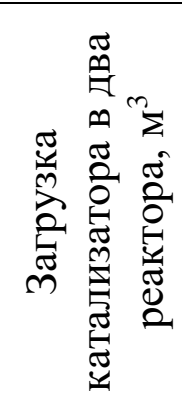 } \\
\hline 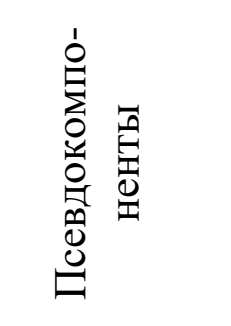 & 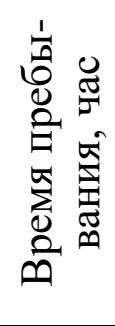 & 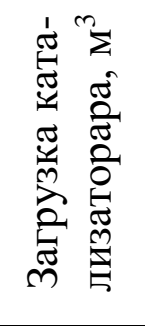 & 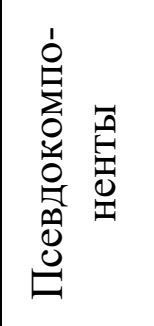 & 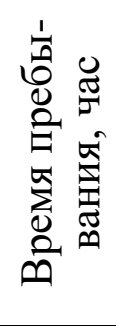 & 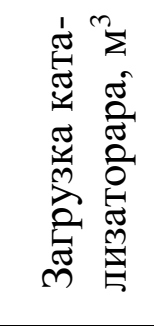 & & 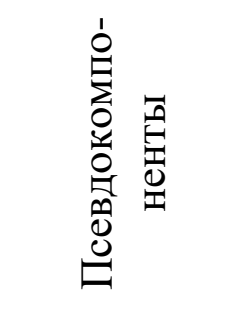 & 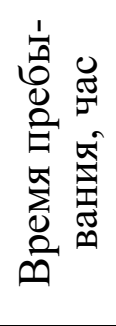 & 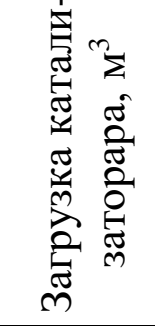 & 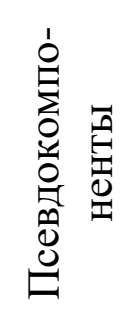 & 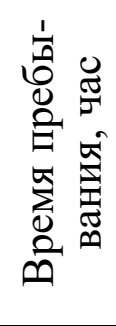 & 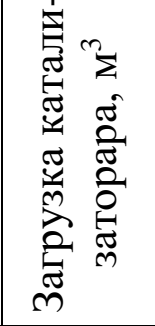 & \\
\hline \multicolumn{7}{|c|}{16 псевдокомпонентов } & \multicolumn{7}{|c|}{8 псевдокомпонентов } \\
\hline 1 & 0.33 & 1.03 & $2 \ldots 16$ & 5.36 & 251.38 & 252.42 & 1 & 0.38 & 2.37 & $2 \ldots 8$ & 6.09 & 266.56 & 268.94 \\
\hline 1,2 & 0.36 & 2.27 & $3 \ldots 16$ & 5.43 & 237.64 & 239.91 & 1,2 & 0.45 & 5.70 & $3 \ldots 8$ & 6.24 & 234.26 & 239.97 \\
\hline $1 \ldots 3$ & 0.38 & 3.65 & $4 \ldots 16$ & 5.50 & 223.68 & 227.33 & $1 \ldots 3$ & 0.54 & 10.18 & $4 \ldots 8$ & 6.42 & 200.91 & 211.10 \\
\hline $1 \ldots 4$ & 0.41 & 5.21 & $5 \ldots 16$ & 5.58 & 209.47 & 214.69 & $1 \ldots 4$ & 0.66 & 16.59 & $5 \ldots 8$ & 6.65 & 166.31 & 182.91 \\
\hline $1 \ldots 5$ & 0.45 & 7.03 & $6 \ldots 16$ & 5.67 & 195.01 & 202.04 & $1 \ldots 5$ & 0.85 & 26.64 & $6 \ldots 8$ & 6.94 & 130.12 & 156.76 \\
\hline $1 \ldots 6$ & 0.48 & 9.17 & $7 \ldots 16$ & 5.76 & 180.26 & 189.44 & $1 \ldots 6$ & 1.19 & 44.70 & 7,8 & 7.34 & 91.82 & 136.52 \\
\hline $1 \ldots 7$ & 0.53 & 11.74 & $8 \ldots 16$ & 5.87 & 165.19 & 176.94 & $1 \ldots 7$ & 1.98 & 86.86 & 8 & 8.03 & 50.24 & 137.10 \\
\hline $1 \ldots 8$ & 0.59 & 14.88 & $9 \ldots 16$ & 5.99 & 149.78 & 164.67 & $1 \ldots 8$ в $\mathrm{P}-1$ & 5.9 & 297.9 & - & - & - & - \\
\hline $1 \ldots 9$ & 0.66 & 18.80 & $10 \ldots 16$ & 6.12 & 133.98 & 152.78 & & & & & & & \\
\hline $1 \ldots 10$ & 0.76 & 23.83 & $11 \ldots 16$ & 6.27 & 117.73 & 141.57 & \multicolumn{7}{|c|}{4 псевдокомпонента } \\
\hline $1 \ldots 11$ & 0.88 & 30.54 & $12 \ldots 16$ & 6.46 & 100.96 & 131.50 & 1 & 0.47 & 5.97 & $2 \ldots 4$ & 6.87 & 257.76 & 263.73 \\
\hline $1 \ldots 12$ & 1.06 & 39.93 & $13 \ldots 16$ & 6.68 & 83.55 & 123.48 & 1,2 & 0.72 & 18.01 & 3,4 & 7.27 & 181.97 & 199.99 \\
\hline $1 \ldots .13$ & 1.32 & 53.99 & $14 \ldots 16$ & 6.97 & 65.36 & 119.36 & $1 \ldots 3$ & 1.31 & 49.13 & 4 & 7.97 & 99.65 & 148.78 \\
\hline $1 \ldots 14$ & 1.76 & 77.42 & 15,16 & 7.37 & 46.11 & 123.53 & $1 \ldots 4$ в P-1 & 6.58 & 329.3 & - & - & - & - \\
\hline $1 \ldots 15$ & 2.65 & 124.27 & 16 & 8.07 & 25.22 & 149.49 & & & & & & & \\
\hline .016 в P-1 & 5.29 & 264.9 & - & - & - & - & & & & & & & \\
\hline
\end{tabular}




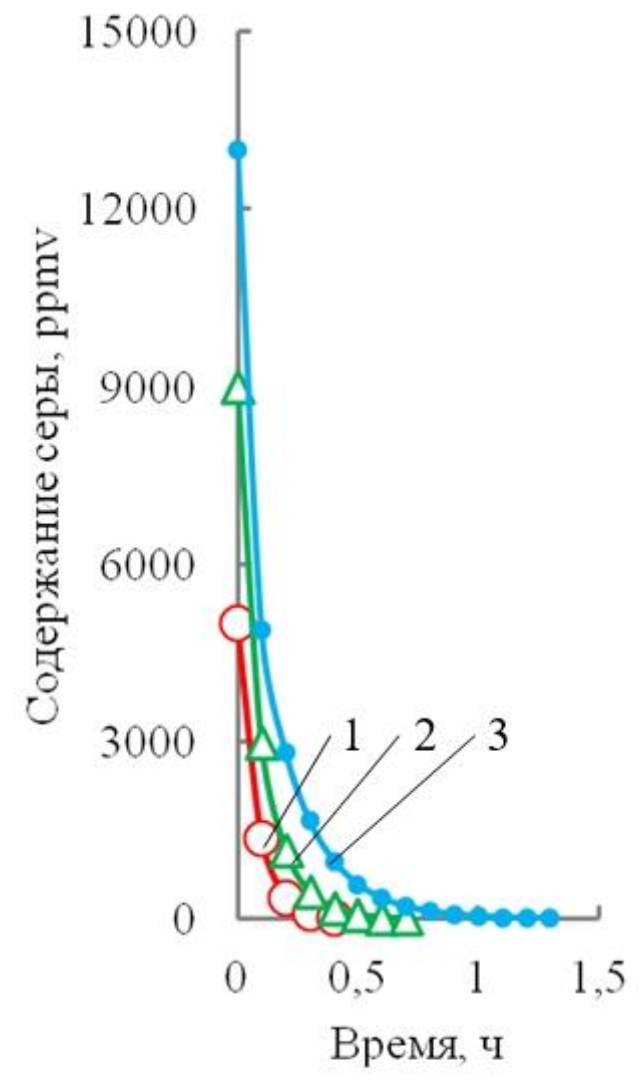

a)

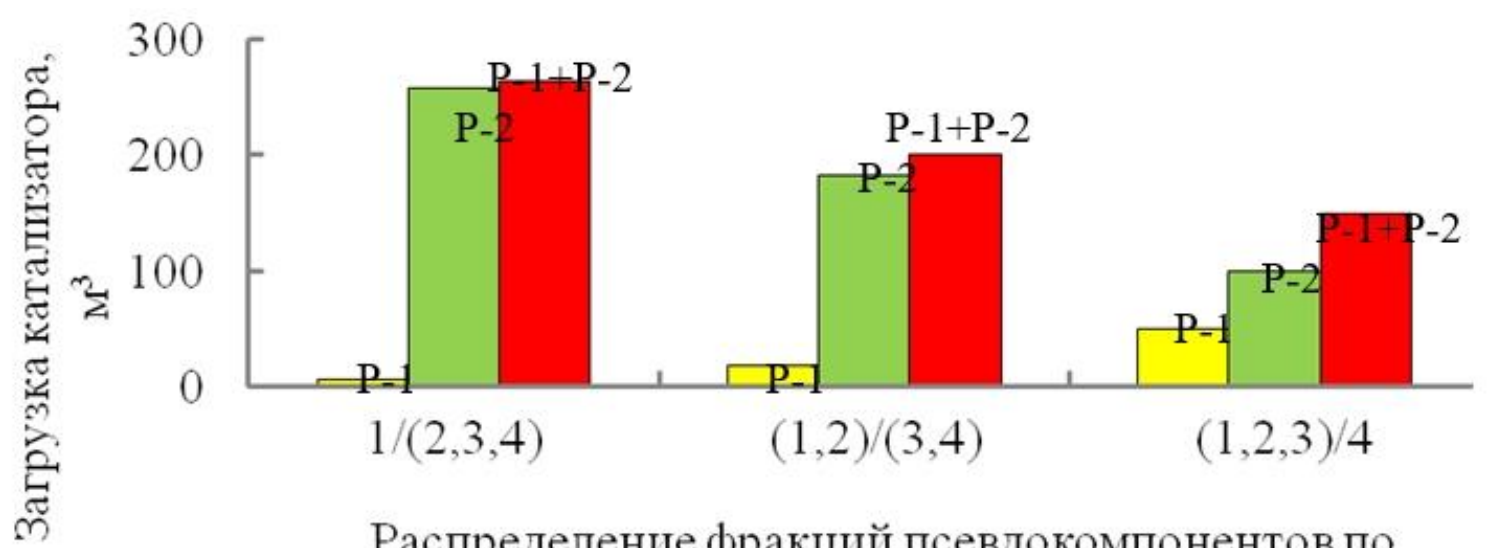

Распределение фракций псевдокомпонентов по реакторам

в)

Рисунок 5. Кинетические кривые при распределении исходного сырья по псевдокомпонентам (1, 2, 3, 4 - номера псевдокомпонентов) по реакторам P-1 и Р-2: в соотношениях $(1,2,3) / 4$ для P-1/P-2 для P-1 (a), в соотношениях $1 /(2,3,4)$ для $\mathrm{P}-1 / \mathrm{P}-2$ для $\mathrm{P}-2$ (б) и гистограмма загрузки катализатора по реакторам (в) для разных распределений фракций псевдокомпонентов 
Таблица 4. Сводные данные по зависимости суммарной загрузки катализатора в два реактора для различных вариантов распределения общей серы в сырье

\begin{tabular}{|c|c|c|c|c|c|c|c|c|}
\hline \multirow[b]{2}{*}{ 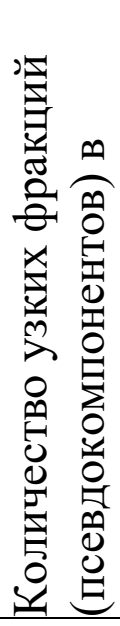 } & \multirow[b]{2}{*}{ 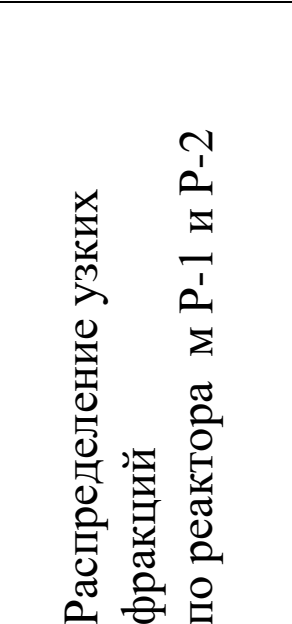 } & \multicolumn{7}{|c|}{$\begin{array}{c}\text { Суммарная загрузка катализатора в двух реакторах, } \\
\text { м³ }^{3} \text { при вариантах распределения общей серы }\end{array}$} \\
\hline & & 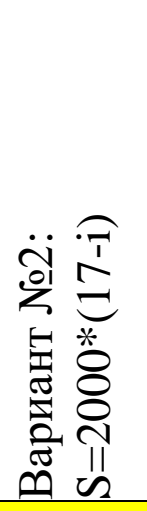 & 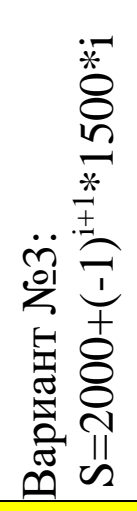 & 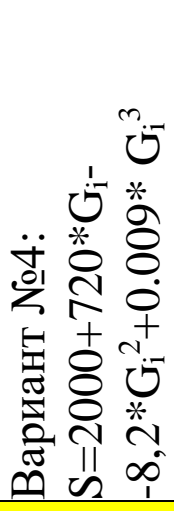 & 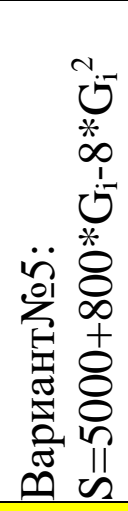 & 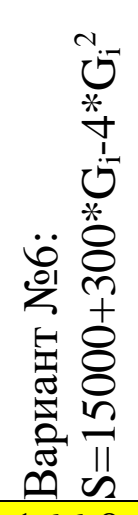 & 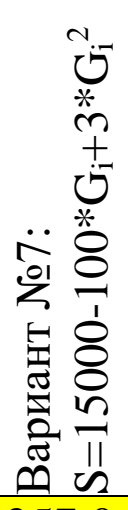 & 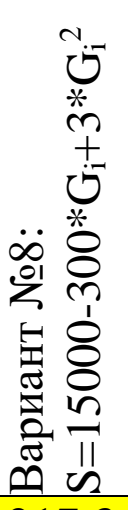 \\
\hline \multirow{16}{*}{16} & $1 / 2 \ldots 16$ & 123.5 & 187.9 & 92.3 & 165.9 & 166.0 & 257.0 & 217.3 \\
\hline & $1,2 / 3 \ldots 16$ & 119.9 & 179.3 & 90.7 & 159.4 & 159.5 & 244.4 & 207.3 \\
\hline & $1 \ldots 3 / 4 \ldots 16$ & 116.2 & 171.6 & 88.9 & 152.8 & 152.9 & 231.5 & 197.0 \\
\hline & $1 \ldots 4 / 5 \ldots 16$ & 112.3 & 162.2 & 87.1 & 146.1 & 146.1 & 218.6 & 186.5 \\
\hline & $1 \ldots 5 / 6 \ldots 16$ & 108.3 & 155.3 & 85.2 & 139.4 & 139.3 & 205.6 & 175.9 \\
\hline & $1 \ldots 6 / 7 \ldots 16$ & 104.2 & 144.7 & 83.3 & 132.7 & 132.5 & 192.6 & 165.1 \\
\hline & $1 \ldots 7 / 8 \ldots 16$ & 100.1 & 139.3 & 81.4 & 126.1 & 125.7 & 179.8 & 154.4 \\
\hline & $1 \ldots 8 / 9 \ldots 16$ & 96.0 & 127.3 & 79.6 & 119.6 & 119.0 & 167.1 & 143.7 \\
\hline & $1 \ldots 9 / 10 \ldots 16$ & 92.0 & 124.5 & 78.0 & 113.4 & 112.5 & 154.9 & 133.2 \\
\hline & $1 \ldots 10 / 11 \ldots 16$ & 88.2 & 110.7 & 76.8 & 107.6 & 106.4 & 143.3 & 123.3 \\
\hline & $1 \ldots 11 / 12 \ldots 16$ & 85.0 & 113.0 & 76.2 & 102.6 & 101.0 & 132.9 & 114.3 \\
\hline & $1 \ldots 12 / 13 \ldots 16$ & 82.5 & 97.3 & 76.6 & 99.0 & 96.9 & 124.7 & 107.0 \\
\hline & $1 \ldots 13 / 14 \ldots 16$ & 81.6 & 112.0 & 78.9 & 97.9 & 95.0 & 120.4 & 103.0 \\
\hline & $1 \ldots 14 / 15,16$ & 84.0 & 96.2 & 84.5 & 101.7 & 98.0 & 124.7 & 106.1 \\
\hline & $1 \ldots 15 / 16$ & 94.0 & 158.2 & 96.3 & 117.4 & 112.8 & 151.2 & 128.0 \\
\hline & $1 \ldots 16$ в P-1 & 126.8 & 196.0 & 93.9 & 172.3 & 172.2 & 269.4 & 227.0 \\
\hline \multirow{8}{*}{8} & $1 / 2 \ldots 8$ & 167.8 & 267.8 & 166.1 & 206.5 & 201.2 & 272.9 & 235.1 \\
\hline & $1,2 / 3 \ldots 8$ & 153.8 & 238.9 & 152.1 & 186.9 & 182.4 & 243.6 & 210.9 \\
\hline & $1 \ldots 3 / 4 \ldots 8$ & 139.5 & 210.2 & 138.1 & 167.4 & 163.3 & 214.1 & 186.2 \\
\hline & $1 \ldots 4 / 5 \ldots 8$ & 125.3 & 182.2 & 124.5 & 148.3 & 144.7 & 185.2 & 161.5 \\
\hline & $1 \ldots 5 / 6 \ldots 8$ & 112.0 & 156.1 & 112.2 & 130.9 & 127.4 & 158.3 & 138.1 \\
\hline & $1 \ldots 6 / 7 \ldots 8$ & 101.9 & 136.0 & 103.7 & 117.9 & 114.2 & 137.6 & 119.7 \\
\hline & $1 \ldots 7 / 8$ & 102.9 & 136.5 & 107.5 & 120.0 & 115.3 & 138.0 & 119.2 \\
\hline & $1 \ldots 8$ в $\mathrm{P}-1$ & 181.2 & 296.7 & 179.9 & 225.9 & 219.7 & 301.8 & 258.6 \\
\hline \multirow{4}{*}{4} & $1 / 2 \ldots 4$ & 199.5 & 262.6 & 207.4 & 229.8 & 221.7 & 266.9 & 233.2 \\
\hline & $1,2 / 3 \ldots 4$ & 157.4 & 199.2 & 162.8 & 178.4 & 172.4 & 202.0 & 177.9 \\
\hline & $1 \ldots 3 / 4$ & 123.2 & 148.2 & 127.8 & 137.7 & 132.9 & 149.6 & 131.5 \\
\hline & $\mathrm{P}-1$ & 241.4 & 327.9 & 253.1 & 282.6 & 271.5 & 332.2 & 0 \\
\hline
\end{tabular}


При разделении сырья на 8 и 4 узкие фракции расчет процесса становится менее чувствительным, и границей деления является температура между последней и предпоследней узкими фракциями. Необходимо также отметить, что при сопоставлении результатов оптимизации при делении сырья на 4, 8 и 16 узких фракций (рисунок 6) расхождения между результатами расчета для вариантов № 1, № 2 и № 3 распределения серы по узким фракциям существенно отличаются.

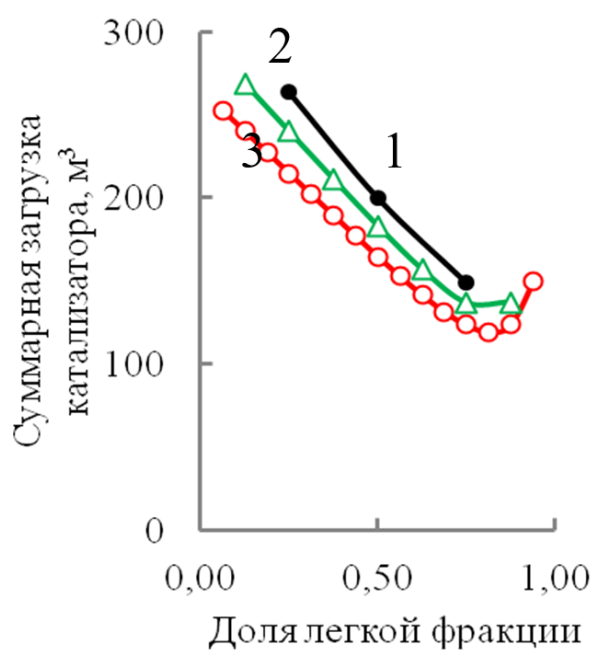

a)

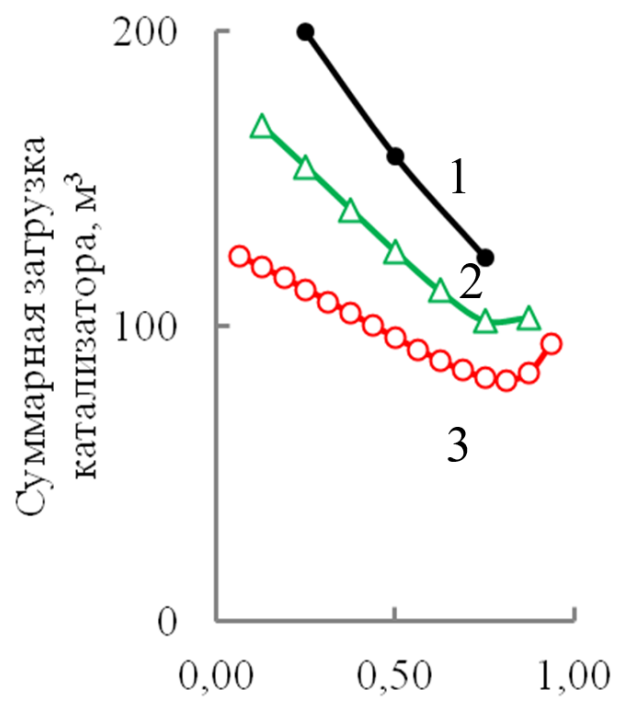

Доля легкой фракции

б)

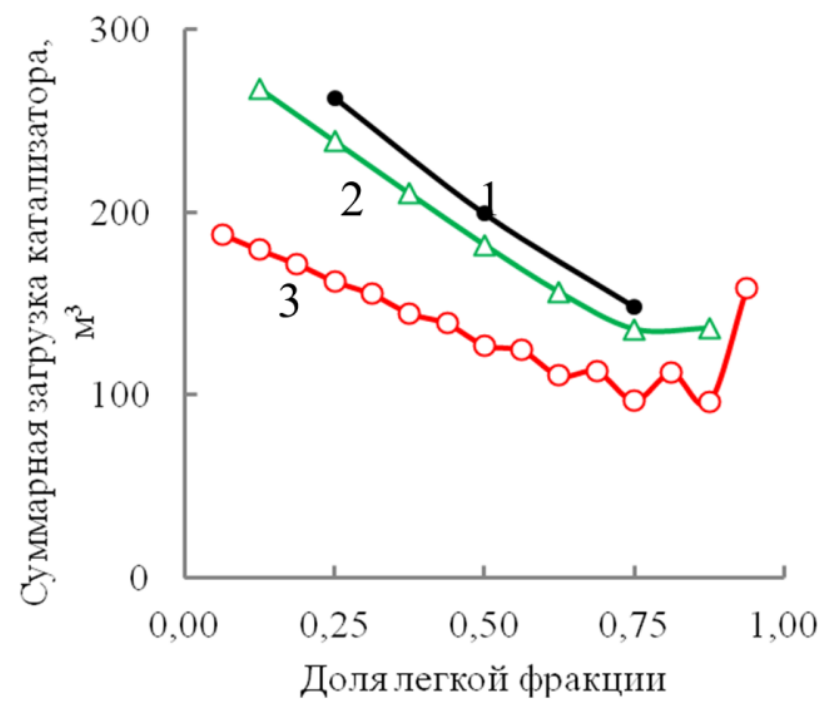

B)

а) сырье № 1; б) сырье № 2; в) сырье № 3

Рисунок 6. Зависимость суммарной загрузки катализатора от доли легкой фракции в сырье для 4 (1), 8 (2) и 16 (3) узких фракций псевдокомпонентов 
Наличие двух минимумов и немонотонность расчетной загрузки катализатора для сырья № 3 в диапазоне доли легкой фракции 0-0.8 на рисунке 6 , в объясняется специфическим законом распределения серы в этом сырье (рисунок 4).

Для вариантов сырья № 4-№ 8 полученные закономерности во многом близки к ранее обсужденным и рассмотренным для иных вариантов составов сырья (рисунок 7).

Следует отметить некоторые характерные особенности гидроочистки дизельного топлива, выявленные в результате математического моделирования процесса.

Отгон широкой легкой фракции от поступающего на гидроочистку сырья, подаваемый в реактор Р-1, оптимально составляет от 81.25 \% до 75 \% об. (рисунки 6, 7), что существенно выше 60 \% об., примененных в [8] и, вероятно, ограниченных особенностями фракционирования на промышленной установке, например, теплоподводом в низ ректификационной колонны, разделяющей исходное сырье.

Заметна относительная близость результатов расчета суммарной загрузки катализатора в два реактора для вариантов сырья № 1, № 7 и № 8 при его представлении 16, 8 и 4 узкими фракциями, в которых трудногидрируемые псевдокомпоненты имеют существенно более высокую концентрацию по сравнению с легкогидрируемыми.

Для вариантов сырья № 2, № 4, № 5 и № 6 уменьшение числа узких фракций в два раза вызывает почти одинаковый градиент увеличения загрузки катализатора, связанный с тем, что трудногидрируемые псевдокомпоненты имеют существенно меньшую концентрацию по сравнению с легкогидрируемыми или среднегидрируемыми псевдокомпонентами. 


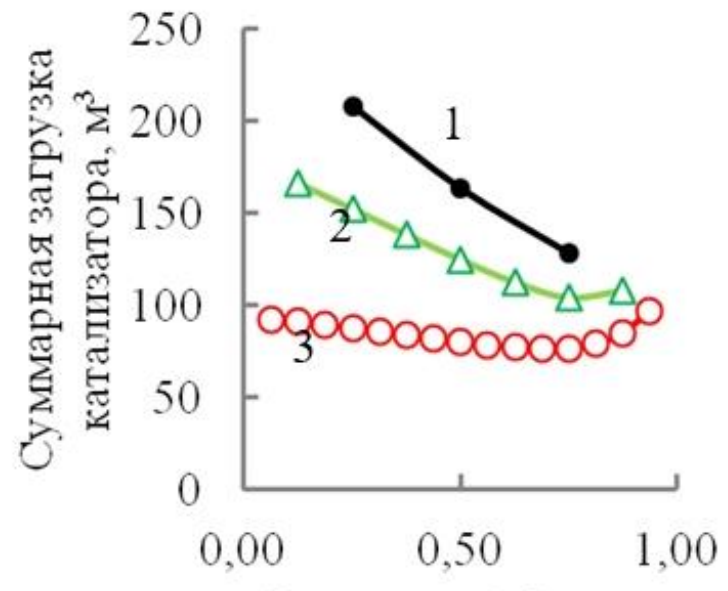

Доля легкой фракцип

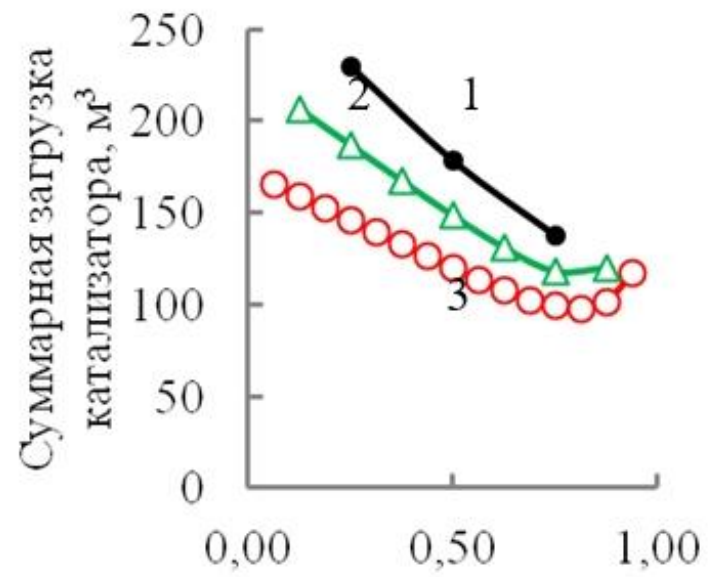

Доля легкой фракции a)

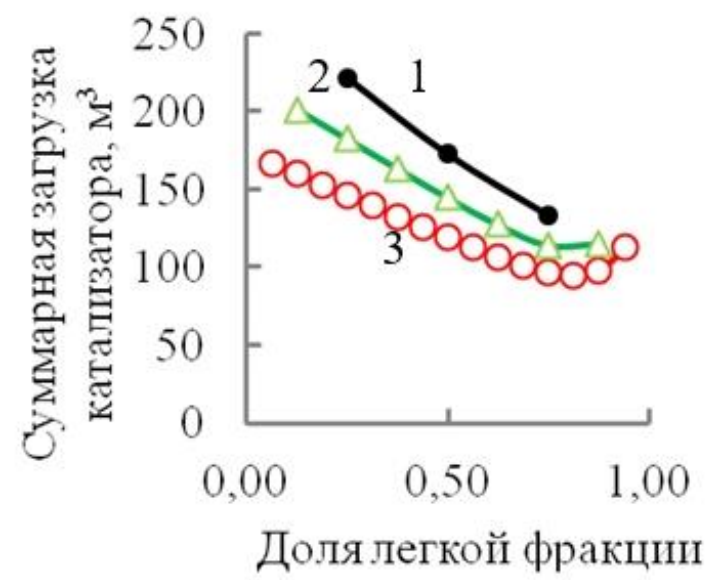

б)

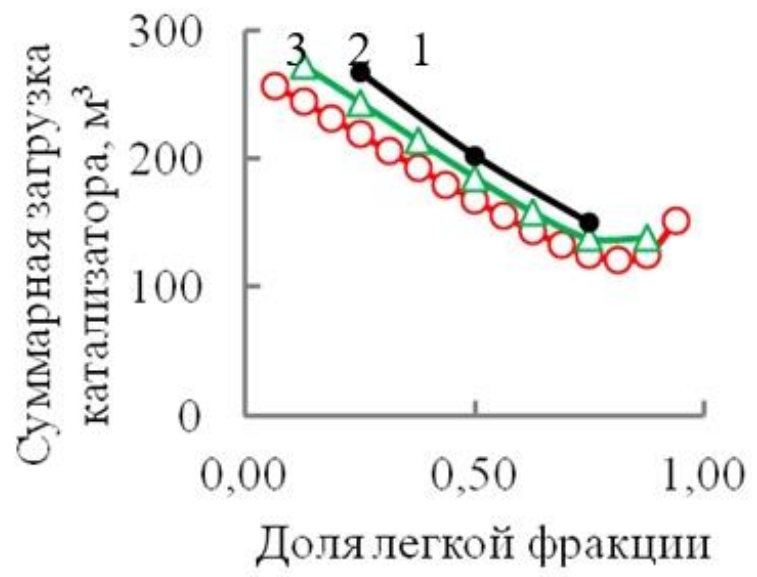

B)

г)

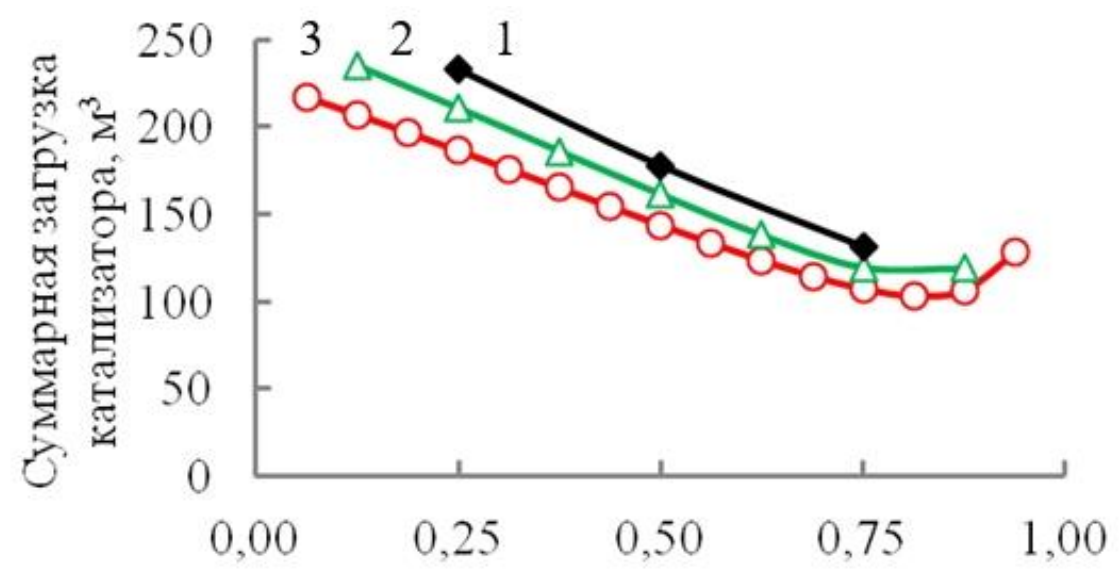

Доля легкой фракцип

д)

а) сырье № 4; б) сырье № 5; в) сырье № 6; г) сырье № 7; д) сырье № 8

Рисунок 7. Зависимость суммарной загрузки катализатора от доли легкой фракции в сырье для 4 (1), 8 (2) и 16 (3) узких фракций псевдокомпонентов 
Загрузка катализатора в два реактора при раздельном гидрировании сырья всегда ниже, чем в один реактор или в эквивалентной ему схеме с несколькими параллельно или последовательно работающими реакторами.

Оптимальную границу деления сырья на широкие легкую и тяжелую фракции можно уточнить, дополнив расчетные данные, полученные в ходе математического моделировании, графоаналитическим анализом, что позволяет рассчитать реакторы с практически одинаковой загрузкой катализатора, более удобными с позиций конструирования и изготовления реакторов (рисунок 8 ).

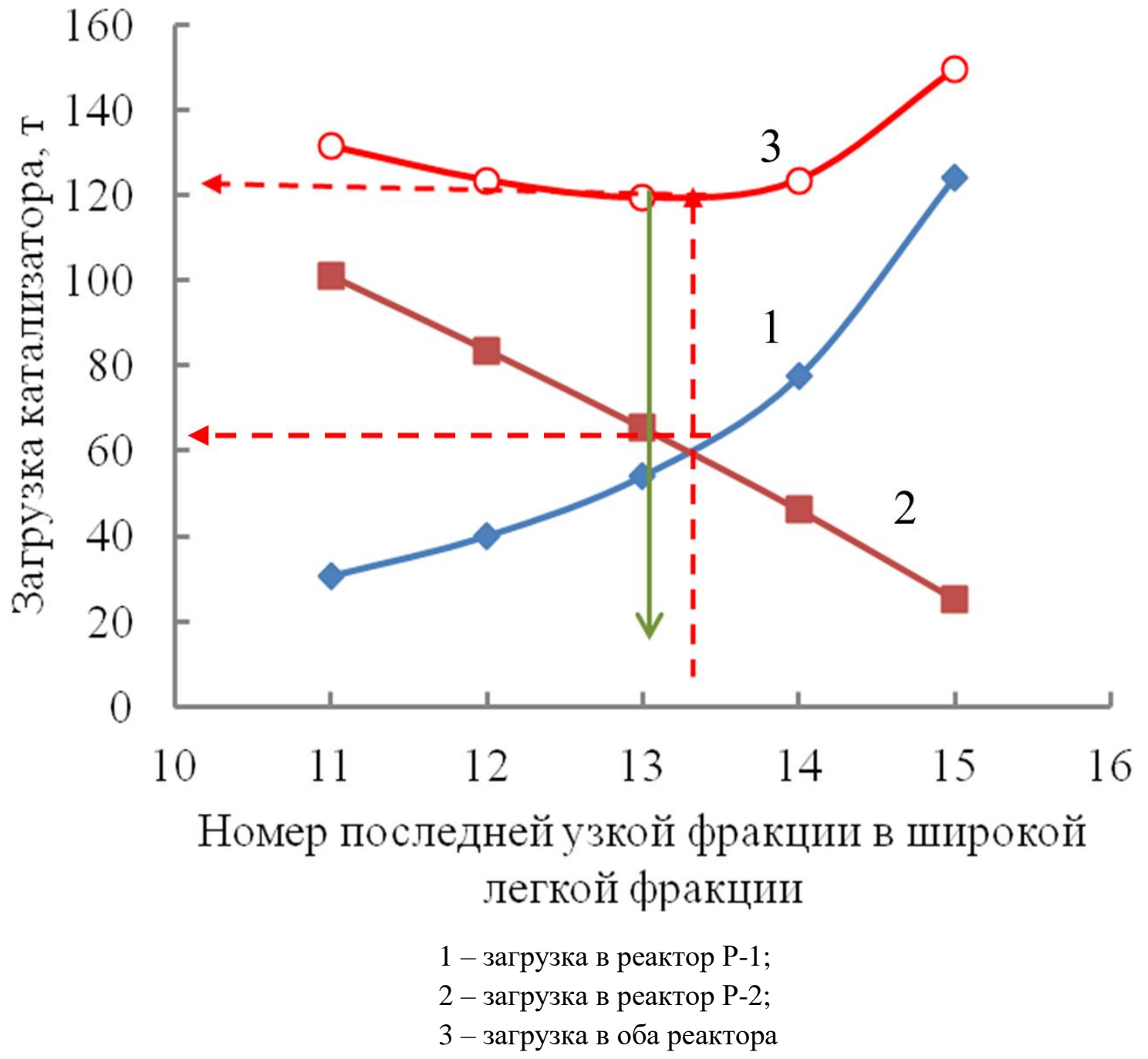

Рисунок 8. К расчету равных загрузок катализатора в реакторы

Математическая модель с дискретизацией узких фракций (таблица 3) показала, что границей деления сырья является 13-я узкая фракция с концом 
кипения $315{ }^{\circ} \mathrm{C}$, тогда получаем широкие легкую фракцию по кривой ИТК (рисунок 3) н.к.-315 ${ }^{\circ} \mathrm{C}$ и тяжелую фракцию $315-360{ }^{\circ} \mathrm{C}$ с загрузкой катализатора в реакторы Р-1 и Р-2 соответственно 54.0 т и 65.4 т и суммарной загрузкой 119.4 т. Графоаналитическая коррекция по рисунку 8 позволяет рекомендовать разделение 14-й узкой фракции по температуре $320{ }^{\circ} \mathrm{C}$ с получением широких легкой фракции по кривой ИТК (рисунок 3) н.к.-320 ${ }^{\circ} \mathrm{C}$ и тяжелой фракции 320-360 ${ }^{\circ} \mathrm{C}$ с равными загрузками катализатора в реакторы Р-1 и Р-2 по 59.5 т катализатора в каждый с суммарной загрузкой 119 т.

\section{Выводы}

1. В ходе математического моделирования процесса раздельной гидроочистки предварительно фракционированного на широкие легкую и тяжелую фракции сырья в двух реакторах выполнено 200 вариантов расчетов гидроочистки дизельного топлива с исследованием влияния деления исходного сырья на 16, 8 и 4 узких фракций, в которых совокупные сераорганические компоненты рассматривались как псевдокомпоненты, и 8 разнообразных распределений сераорганики по узким фракциям на загрузку катализатора в реакторы.

2. Гидроочистка дизельного топлива с предварительным делением сырья на широкие легкую и тяжелую фракции с их последующим гидрированием в двух реакторах обеспечивается существенно меньшей загрузкой катализатора, чем при гидроочистке всего сырья в одном реакторе или любых иных многореакторных схемах, эквивалентных по условиям гидроочистке дизельного топлива в одном реакторе.

3. Уменьшение числа расчетных узких фракций с 16 до 4 понижает точность расчета и приводит к чрезмерному расчетному завышению загрузки катализатора в реакторы, однако, если в исходном сырье трудногидрируемые псевдокомпоненты имеют существенно более высокую концентрацию по сравнению с легкогидрируемыми, то это приводит к 
снижению уровня погрешности расчетов, связанного с числом используемых узких фракций.

4. Сочетание методов математического моделирования и графоаналитического расчета позволяет разработать реакторный блок установки гидроочистки дизельного топлива с равной загрузкой катализатора в реакторы.

\section{Список используемых источников}

1. Особенности рынков нефтепродуктов // Нефтяной рынок: Просто о сложном. Приложение к журналу «Сибирская нефть». 2019. № 7. С. 28-32.

2. ГОСТ 32511-2013. Топливо дизельное ЕВРО. Технические условия. М.: Стандартинформ, 2019. 39 с.

3. Мановян А.К. Технология первичной переработки нефти и природного газа. М.: Химия, 2001. 568 с.

4. Гаврилов Н.В., Дуров О.В., Сорокин Ю.Б., Сыркин А.М. Определение причин повышенного содержания серы в продукте гидроочистки сырья риформинга // Башкирский химический журнал. 2008. Т. 15. № 2. C. $110-113$.

5. Руденко А.В. Повышение эффективности процесса гидроочистки дизельного топлива // Актуальные проблемы гуманитарных и естественных наук. 2014. № 5-1. С. 25-27.

6. Рудин М.Г., Сомов В.Е., Фомин А.С. Карманный справочник нефтепереработчика. М.: ЦНИИТЭнефтехим, 2004. 336 с.

7. Логинов С.А., Капустин В.М., Луговской А.И., Рудяк К.Б., Лебедев Б.Л. Промышленное производство высококачественных дизельных топлив с содержанием серы 0.035 и 0.05 \% // Нефтепереработка и нефтехимия. Научно-технические достижения и передовой опыт. 2001. № 11. C. 57-61. 
8. Логинов С.А., Лебедев Б.Л., Капустин В.М., Луговской А.И., Курганов В.М., Рудяк К.Б. Разработка новой технологии процесса гидрообессеривания дизельных топлив // Нефтепереработка и нефтехимия. Научно-технические достижения и передовой опыт. 2001. № 11. С. 67-74.

9. Танатаров М.А., Ахметшина М.Н., Фасхутдинов Р.А., Волошин Н.Д., Золотарев П.А. Технологические расчеты установок переработки нефти. М.: Химия, 1987. 350 с.

10. Великов С.В., Покровская С.В., Булавка Ю.А. Кинетические закономерности процесса гидрообессеривания дизельного топлива на установке Л-24/6 // Вестник Полоцкого университета. Серия В. Промышленность. Прикладные науки. 2014. № 11. С. 153-159.

11. Афанасьева Ю.И., Кривцова Н.И., Иванчина Э.Д., Занин И.К., Татаурщиков А.А. Разработка кинетической модели процесса гидроочистки дизельного топлива // Известия Томского политехнического университета. 2012. T. 321. № 3. C. 121-125.

12. Чузлов В.А., Долганов И.М., Иванчина Э.Д., Ивашкина Е.Н., Кривцова Н.И., Коткова Е.П. Интеллектуальная гидроочистка // Деловой журнал «Neftegaz.RU». 2020. № 9 (105). C. 38-44.

13. Кривцова Н.И., Кривцов Е.Б., Иванчина Э.Д., Головко А.К. Кинетические закономерности гидрообессеривания дизельной фракции // Фундаментальные исследования. 2013. № 8-3. С. 640-644.

14. Xun Tang, Shuyuan Li, Changtao Yue, Jilai He, Jili Hou Lumping Kinetics of Hydrodesulfurization and Hydrodenitrogenation of the Middle Distillate from Chinese Shale Oil // Oil Shale. 2013. Vol. 30. No. 4. P. 517-535.

15. Лебедев Б.Л., Логинов С.А., Коган О.Л., Лобзин Е.В., Капустин В.М., Луговской А.И., Рудяк К.Б. Исследование состава и реакционноспособности сернистых соединений в процессе гидрообессеривания на промышленной установке // Нефтепереработка и нефтехимия. Научно-технические достижения и передовой опыт. 2001. № 11. С. 62-67. 
16. Пат. 2691965 РФ, МПК С 10 G 65/14. Способ гидроочистки дизельного топлива / И.А. Мнушкин, Н.А. Самойлов, В.А. Жилина. 2019102093, Заявлено 25.01.2019; Опубл. 19.06.2019. Бюл. 17.

\section{References}

1. Osobennosti rynkov nefteproduktov [Features of the oil Product Markets]. Neftyanoi rynok: Prosto o slozhnom. Prilozhenie $k$ zhurnalu «Sibirskaya neft'» [Oil Market: Just About the Complex. Appendix to the Journal «Siberian Oil»]. 2019, No. 7, pp. 28-32. [in Russian].

2. GOST 32511-2013. Toplivo dizel'noe EVRO. Tekhnicheskie usloviya [State Standard 32511-2013. Diesel Fuel EURO. Specifications]. Moscow, Standartinform Publ., 2019. 39 p. [in Russian].

3. Manovyan A.K. Tekhnologiya pervichnoi pererabotki nefti i prirodnogo gaza [Primary Oil and Natural Gas Processing Technology]. Moscow, Khimiya Publ., 2001. 568 p. [in Russian].

4. Gavrilov N.V., Durov O.V., Sorokin Yu.B., Syrkin A.M. Opredelenie prichin povyshennogo soderzhaniya sery $\mathrm{v}$ produkte gidroochistki syr'ya riforminga [Definition of the Reasons of the Raised Contents of Sulfur at Hydroclearing Reforming Feed]. Bashkirskii khimicheskii zhurnal - Bashkir Chemical Journal, 2008, Vol. 15, No. 2, pp. 110-113. [in Russian].

5. Rudenko A.V. Povyshenie effektivnosti protsessa gidroochistki dizel'nogo topliva [Improving the Efficiency of the Diesel Hydrotreating Process]. Aktual'nye problemy gumanitarnykh i estestvennykh nauk - Actual Problems of the Humanities and Natural Sciences, 2014, No. 5-1, pp. 25-27. [in Russian].

6. Rudin M.G., Somov V.E., Fomin A.S. Karmannyi spravochnik neftepererabotchika [Refinery Pocket Guide]. Moscow, TsNIITEneftekhim Publ., 2004. 336 p. [in Russian]. 
7. Loginov S.A., Kapustin V.M., Lugovskoi A.I., Rudyak K.B., Lebedev B.L. Promyshlennoe proizvodstvo vysokokachestvennykh dizel'nykh topliv $\mathrm{s}$ soderzhaniem sery 0.035 i $0.05 \%$ [Industrial Production of High Quality Diesel Fuels with a Sulfur Content of 0.035 and $0.05 \%$ ]. Neftepererabotka $i$ neftekhimiya. Nauchno-tekhnicheskie dostizheniya i peredovoi opyt - Oil Processing and Petrochemistry, 2001, No. 11, pp. 57-61. [in Russian].

8. Loginov S.A., Lebedev B.L., Kapustin V.M., Lugovskoi A.I., Kurganov V.M., Rudyak K.B. Razrabotka novoi tekhnologii protsessa gidroobesserivaniya dizel'nykh topliv [Development of a New Technology for the Process of Hydrodesulfurization of Diesel Fuels]. Neftepererabotka $i$ neftekhimiya. Nauchno-tekhnicheskie dostizheniya i peredovoi opyt - Oil Processing and Petrochemistry, 2001, No. 11, pp. 67-74. [in Russian].

9. Tanatarov M.A., Akhmetshina M.N., Faskhutdinov R.A., Voloshin N.D., Zolotarev P.A. Tekhnologicheskie raschety ustanovok pererabotki nefti [Technological Calculations of Oil Refining Units]. Moscow, Khimiya Publ., 1987. 350 p. [in Russian].

10. Velikov S.V., Pokrovskaya S.V., Bulavka Yu.A. Kineticheskie zakonomernosti protsessa gidroobesserivaniya dizel'nogo topliva na ustanovke L24/6 [Kinetic Regularities of Hydrodesulfurization of Diesel Fuel Atthe L-24/6]. Vestnik Polotskogo universiteta. Seriya V. Promyshlennost'. Prikladnye nauki Herald of Polotsk State University. Series B. Industry. Applied Sciences, 2014, No. 11, pp. 153-159. [in Russian].

11. Afanaseva Yu.I., Krivtsova N.I., Ivanchina E.D., Zanin I.K., Tataurshchikov A.A. Razrabotka kineticheskoi modeli protsessa gidroochistki dizel'nogo topliva [Development of a Kinetic Model of the Diesel Fuel Hydrotreating Process]. Izvestiya Tomskogo politekhnicheskogo universiteta Bulletin of the Tomsk Polytechnic University, 2012, Vol. 321, No. 3, pp. 121-125. [in Russian]. 
12. Chuzlov V.A., Dolganov I.M., Ivanchina E.D., Ivashkina E.N., Krivtsova N.I., Kotkova E.P. Intellektual'naya gidroochistka [Intelligent Hydrotreating]. Delovoi zhurnal «Neftegaz.RU» - Business Magazine «Neftegaz.RU», 2020, No. 9 (105), pp. 38-44. [in Russian].

13. Krivtsova N.I., Krivtsov E.B., Ivanchina E.D., Golovko A.K. Kineticheskie zakonomernosti gidroobesserivaniya dizel'noi fraktsii [Kinetic Regularities of Hydro-Desulfurization of Diesel Fuel]. Fundamental'nye issledovaniya - Fundamental Research, 2013, No. 8-3, pp. 640-644. [in Russian].

14. Xun Tang, Shuyuan Li, Changtao Yue, Jilai He, Jili Hou Lumping Kinetics of Hydrodesulfurization and Hydrodenitrogenation of the Middle Distillate from Chinese Shale Oil. Oil Shale, 2013, Vol. 30, No. 4, pp. 517-535.

15. Lebedev B.L., Loginov S.A., Kogan O.L., Lobzin E.V., Kapustin V.M., Lugovskoi A.I., Rudyak K.B. Issledovanie sostava i reaktsionnosposobnosti sernistykh soedinenii $\mathrm{v}$ protsesse gidroobesserivaniya na promyshlennoi ustanovke [Study of the Composition and Reactivity of Sulfur Compounds in the Process of Hydrodesulfurization at an Industrial Plant]. Neftepererabotka $i$ neftekhimiya. Nauchno-tekhnicheskie dostizheniya i peredovoi opyt - Oil Processing and Petrochemistry, 2001, No. 11, pp. 62-67. [in Russian].

16. Mnushkin I.A., Samoilov N.A., Zhilina V.A. Sposob gidroochistki dizel'nogo topliva [Diesel Fuel Hydrotreating Method]. Patent RF, No. 2691965, 2019. [in Russian]. 


\section{Сведения об авторах}

\section{About the authors}

Жилина Валерия Анатольевна, аспирант кафедры «Нефтехимия и химическая технология», УГНТУ, г. Уфа, Российская Федерация

Valeria A. Zhilina, Post-graduate Student of Petrochemistry and Chemical Technology Department, USPTU, Ufa, Russian Federation

e-mail: ofelia90@mail.ru

Самойлов Наум Александрович, д-р техн. наук, профессор кафедры «Нефтехимия и химическая технология», УГНТУ, г. Уфа, Российская Федерация

Naum A. Samoilov, Doctor of Engineering Sciences, Professor of Petrochemistry and Chemical Technology Department, USPTU, Ufa, Russian Federation

e-mail: naum.samoilow@yandex.ru 